\title{
Pneumoperitônio Pós-Cesárea: Relato de Caso
}

\author{
Pneumoperitoneum After Cesarean Section: A Case Report
}

\begin{abstract}
Melania Maria Ramos de Amorim, Fernando Antônio Campelo Spencer Netto
\end{abstract}
Luiz Carlos Santos, Everaldo Mascarenhas, Leila Katz

\section{RESUM0}

A associação de pneumoperitônio, dor abdominal e íleo paralítico no período pós-operatório relaciona-se, na maioria dos casos, à perfuração de vísceras ocas. Os autores apresentam um caso de pós-operatório de cesariana por DPPNI em que a paciente evoluiu com importante distensão e dor abdominal. Realizada radiografia de tórax e abdome evidenciou-se importante dilatação das alças de intestino grosso e delgado e pneumoperitônio, foi submetida a laparotomia exploradora com a hipótese diagnóstica de perfuração intestinal. Na cirurgia, no entanto, não foi encontrada lesão gastrintestinal; foi confirmado o diagnóstico de pneumoperitônio, identificando-se hemoperitônio e hematoma subaponeurótico infectados (E. coli). A evolução pós-operatória foi satisfatória, mantendo-se antibioticoterapia (ceftriaxona + metronidazol) por 4 dias. A paciente teve alta no $7^{\circ}$ dia pós-laparotomia. Depois de revisão da literatura pertinente, os autores concluem que o presente caso de pneumoperitônio relacionou-se possivelmente à infecção por bactéria produtora de gás em paciente com quadro clínico de íleo paralítico.

PALAVRAS-CHAVE: Pneumoperitônio. Cirurgia. Complicações cirúrgicas. Cesariana. Puerpério. Abdome agudo.

\section{Introdução}

A presença de ar livre na cavidade peritoneal (pneumoperitônio) encontra-se geralmente associada a perfurações do trato gastrintestinal ${ }^{6,13}$, representando, portanto, uma emergência cirúrgica. No entanto, outras causas de

Instituto Materno-Infantil de Pernambuco (IMIP) - Centro de Atenção à Mulher (CAM)

Correspondência:

Melania Maria Ramos de Amorim

Instituto Materno-Infantil de Pernambuco - Coordenação de Ensino

Rua dos Coelhos, 300 - Boa Vista

CEP: 50070-530 - Recife - PE

e-mail: andfpc@br.homeshopping.com.br pneumoperitônio têm sido descritas ${ }^{6,10}$, destacando-se a peritonite espontânea por bactérias produtoras de gás $s^{3,11}$, o pós-operatório de cirurgias abdominais ${ }^{15,17}$ e doenças diversas (pneumomediastino, pneumatose intestinal, esclerodermia) $^{9}$.

O pneumoperitônio pós-operatório pode ser observado no seguimento de cirurgias abdominais e sua formação e duração não parecem relacionadas nem com processos inflamatórios nem com fenômenos oclusivos mecânicos ou paralíticos, dependendo, porém, da magnitude da manipulação cirúrgica ${ }^{17}$. A evolução é normalmente benigna, com diminuição progressiva da quantidade de ar intraabdominal e resolução média dentro de 4-5 dias. A incidência é variável, entre $25-77 \%{ }^{1,8}$. 
O diagnóstico é habitualmente realizado pela radiografia (tórax e abdome), sendo o achado mais freqüente a presença de ar intraperitoneal no quadrante superior direito do abdome ${ }^{12}$. O pneumoperitônio torna-se radiologicamente evidente quando a quantidade de ar no abdome oscila entre $30-90 \mathrm{~cm}^{3}{ }^{17}$. Alguns autores preconizam a tomografia computadorizada como um método de maior sensibilidade ${ }^{5}$, ao passo que outros estudos indicam a ecografia em casos selecionados ${ }^{4}$.

No presente estudo, os autores apresentam um caso de pneumoperitônio diagnosticado no pósoperatório de cesariana em paciente com DPPNI, assistida no Centro de Atenção à Mulher do IMIP.

\section{Relato do Caso}

Paciente de 26 anos, branca, casada, do lar, $1^{\circ}$ grau incompleto, natural e procedente de RecifePE. História Clínica: paciente gesta ix para iv (4 partos normais, 4 abortamentos), admitida no CAM-IMIP em 24/07 / 1997 com gestação no curso da $31^{a}$ semana e quadro clínico de sangramento genital abundante e choque hipovolêmico, ausculta fetal negativa. Submetida a operação cesariana com hipótese diagnóstica de Descolamento Prematuro da Placenta Normalmente Inserida (DPPNI), foi realizada hemotransfusão. Na cesariana (incisão à Pfannenstiel) foi retirado feto morto, pesando 1460 gramas. Evidenciou-se sangramento aumentado pela incisão, sobretudo no nível de tecido celular subcutâneo.

No pós-operátorio da cesareana apresentou sangramento discreto pela ferida operátoria (FO) no primeiro dia (DPO) e evoluiu com coagulopatia. Foi submetida a hemotransfusão (hemácias + plasma fresco congelado). Abdome flácido e depressível no primeiro e segundo DPO, ruídos hidroaéreos (RHA) presentes, evacuações ausentes. Útero com involução satisfatória, bem contraído, loquiação fisiológica. No $3^{\circ}$ DPO passou a apresentar distensão abdominal moderada e hipoatividade dos RHA. Leucograma normal $\left(12400 / \mathrm{mm}^{3}\right.$, sem desvio), hematócrito de $25 \%$, potássio $(\mathrm{K})$ de $2,8 \mathrm{mEq} / 1$ e radiografia de tórax e abdome evidenciando moderada distensão das alças intestinais (sem pneumoperitônio). Foi introduzida sonda nasogástrica (SNG), suspendendo-se a dieta e iniciando-se reposição de potássio ( $100 \mathrm{mEq} /$ dia).

No $4^{\circ}$ DPO a paciente persistia ainda sem evacuar, com boa diurese, sem distermias, drenagem pela $\mathrm{SNG}=400 \mathrm{ml}$. Distensão abdominal importante, abdome difusamente doloroso à palpação, ausentes ruídos hidroaéreos. Útero contraído, fundo uterino no nível da cicatriz umbilical, lóquios fisiológicos. Foram realizados os seguintes exames: hematócrito: $26 \%$; uréia: $25 \mathrm{mg} \%$; creatinina: 0,6 mg\%; ácido úrico: 5,6 mg\%; $\mathrm{K}: 4,2 \mathrm{mEq} / 1$. Os achados radiológicos eram de distensão de alças de intestino delgado e grosso, sem evidências de pneumoperitônio. Hipótese diagnóstica de obstrução intestinal. Foi realizada punção de subclávia direita para introdução de cateter e aferição da pressão venosa central (PVC). Acrescentou-se cimetidina à prescrição.

Em 29/07/97 (5 ${ }^{\circ}$ DPO), observou-se aumento importante da distensão abdominal, dor difusa à palpação abdominal, ausentes sinais de irritação peritoneal. RHA ausentes. Estado geral regular, hipocorada $(+/ 4+)$, hidratada, afebril, bem perfundida. Útero bem contraído, no nível da cicatriz umbilical. Ferida operatória com bom aspecto, sem drenagem de secreção. Lóquios fisiológicos. Encontrava-se então com hematócrito de $28 \%$ e leucograma com $29000 / \mathrm{mm}^{3}$, sem desvio à esquerda, potássio de $4,6 \mathrm{mg} \%$, níveis em ascensão de uréia (66 mg\%), creatinina $(0,9 \mathrm{mg} \%$ ) e ácido úrico $(8,5 \mathrm{mg} \%)$.

A ultra-sonografia abdominal e pélvica desse dia mostrou coleção líquida de aproximadamente $6,0 \mathrm{~cm}$ de diâmetro em ferida operatória, de provável localização subaponeurótica, devendo corresponder a hematoma. Pequena quantidade de líquido livre na cavidade abdominal. A radiografia de abdome evidenciou grande distensão das alças de intestino grosso e delgado, níveis hidroaéreos e diâmetro do ceco de aproximadamente $10 \mathrm{~cm}$. A radiografia de tórax apresentou imagem de pneumoperitônio importante.

Com a hipótese diagnóstica de perfuração intestinal foi indicada laparotomia exploradora de emergência e iniciada antibioticoterapia com ceftriaxona. Para laparotomia foi realizada incisão mediana transumbilical, sem atingir a incisão prévia à Pfannenstiel. Grande quantidade de ar na cavidade abdominal, saindo sob pressão. Alças de intestino delgado e grosso bastante distendidas, porém não foi encontrada perfuração em qualquer segmento do trato gastrintestinal. Ausentes coleções purulentas. Moderada quantidade de sangue (hemoperitônio) no fundo-de-saco de Douglas. Útero puerperal de coloração e consistência normais, em involução, bem contraído. Anexos normais. Realizada ordenha das alças. Foi ainda realizada exploração da ferida operatória à Pfannenstiel, com drenagem de hematoma subcutâneo e subaponeurótico (infectado). Coletado o sangue da cavidade e da parede para cultura. 
Após a laparotomia foi mantida a sonda nasogástrica, com dieta zero e reposição volêmica sob controle da PVC. Associado metronidazol ao esquema antibiótico. A paciente apresentou evolução satisfatória, com diminuição progressiva da distensão abdominal e resolução do pneumoperitônio, sem hipertermia. Ferida operatória com bom aspecto. Passou a cursar com elevação dos níveis tensionais, em torno de 150x100, sendo realizada proteinúria de fita, que foi positiva (3+), o que levou à hipótese diagnóstica de Doença Hipertensiva Específica da Gestação (DHEG), possivelmente mascarada, até então, pela hipovolemia conseqüente ao DPPNI e às manifestações hemorrágicas no puerpério.

A cultura do líquido peritoneal mostrou crescimento de Escherichia coli (cultura realizada apenas sob condições aeróbias, não incluindo germes anaeróbios). As radiografias de controle realizados em 30/07/97 mostravam ainda moderada distensão de alças intestinais, com discreto pneumoperitônio. No dia 01/08/97, foram encontradas alças intestinais de diâmetro normal, e pneumoperitônio ausente.

No $2^{\circ}$ dia pós-laparotomia, foi retirada a sonda nasogástrica e reinstituída a dieta, uma vez presentes ruídos hidroaéreos. A antibioticoterapia (ceftriaxona + metronidazol) foi mantida por 4 dias, sendo retirada após observação de curva térmica normal e leucograma sem alterações. Alta hospitalar foi dada em 5/8/97 em condições satisfatórias.

As hipóteses diagnósticas quando da alta foram:

1. DHEG grave - DPPNI.

2. Hemoperitônio - Hematoma subaponeurótico (com infecção secundária).

3. Anemia aguda (Politransfundida).

4. Íleo paralítico.

5. Pneumoperitônio pós-operatório - associado provavelmente à infecção por Escherichia coli.

\section{Discussão}

O presente caso constitui uma apresentação peculiar de pneumoperitônio no pós-operatório de cesárea, associado a importante distensão de alças intestinais, que levou à hipótese diagnóstica pré-operatória de perfuração intestinal. $\mathrm{Na}$ laparotomia, entretanto, a par do pneumoperitônio, evidenciou-se apenas hemoperitônio (infectado) e dilatação das alças intestinais, não se encontrando qualquer indício de perfuração do trato gastrintestinal.
Embora o pneumoperitônio possa ser encontrado no pós-operatório de cesárea sem outras complicações associadas, a causa mais freqüente é inequivocamente a perfuração de vísceras ocas. A perfuração espontânea do cécum depois de uma cesariana foi já descrita por diversos autores ${ }^{16}$, conseqüente à pseudo-obstrução colônica aguda (Síndrome de Ogilvie) ${ }^{14}$.

Esta situação constitui uma forma severa de íleo paralítico, em que ocorre grande distensão do cólon na ausência de lesões obstrutivas; embora a etiopatogenia seja desconhecida, suspeita-se de um distúrbio autonômico subjacente (bloqueio parassimpático) ${ }^{2}$; a perfuração cecal é uma complicação potencialmente letal, acarretando em geral a necessidade de hemicolectomia direita ou de cecostomia ${ }^{7}$. O risco de perfuração sobreleva-se nos casos em que o diâmetro do ceco atinge ou ultrapassa os $10 \mathrm{~cm}^{7}$, o que foi um achado no presente caso.

A infecção peritoneal por bactérias produtoras de gás constitui outra causa de pneumoperitônio complicando o período pósoperatório de cesariana, bem como de outras cirurgias $^{3,11}$. Nesse caso que apresentamos, ocorreu infecção abdominal secundária ao hemoperitônio, uma complicação freqüente nas cesarianas em pacientes com pré-eclâmpsia, sobretudo quando associada ao DPPNI. O hemoperitônio aqui seria decorrente do hematoma da ferida operatória drenando para o abdome. Verificou-se ainda positividade na cultura do líquido para Escherichia coli, que tem sido descrita na literatura como causa de pneumoperitônio espontâneo ${ }^{3}$. Como não foi realizada cultura para anaeróbios, é provável ainda a hipótese de infecção polimicrobiana com produção de gás por bactérias anaeróbias ${ }^{11}$.

A hipótese de pneumoperitônio residual pós-cesárea parece pouco provável, uma vez que a história natural da doença nesses casos é de redução progressiva do pneumoperitônio ${ }^{11,13}$, ao passo que a paciente em questão cursou inicialmente com achado radiológico de distensão das alças intestinais sem pneumoperitônio, sendo esse último evidenciado apenas no $5^{\circ}$ dia pós-operatório.

Vale ressaltar, outrossim, que a presença de sangue na cavidade abdominal pode acarretar irritação peritoneal. Essa irritação peritoneal pode acarretar íleo paralítico, e a distensão das alças intestinais determinaria a transformação de pneumoperitônio residual em pneumoperitônio tenso.

De qualquer forma, a evolução pós-operatória em que se mantém ou aumenta a quantidade de 
ar intraperitoneal é preocupante, particularmente quando se associam dor abdominal e íleo paralítico, pelo elevado risco de perfuração do trato gastrintestinal ${ }^{15}$. Em tal hipótese, a intervenção cirúrgica não deve ser postergada em face das conseqüências deletérias que adviriam de uma conduta conservadora na presença de ruptura de víscera oca.

Considerando a evolução clínica da paciente e as principais causas de pneumoperitônio pósoperatório, comentadas anteriormente, concluímos que o presente caso de pneumoperitônio relacionou-se possivelmente à infecção por bactéria produtora de gás em paciente com quadro clínico de íleo paralítico.

\section{SUMMARY}

Pneumoperitoneum, abdominal pain and paralytic ileus in the postoperative period are usually related to perforation of the gastrointestinal tract. The authors present a case of a patient submitted to cesarean section (abruptio placentae) who had a postoperative course of abdominal distention and abdominal pain. Abdominal X-ray showed important dilatation of the colon and small bowel. Pneumoperitoneum was seen on chest X-ray. An exploratory laparotomy was performed because of suspicion of intestinal perforation. The operation showed a marked dilatation of bowel, pneumoperitoneum, and infected hemoperitoneum and subaponeurotic hematoma (Escherichia coli), without any perforation. Postoperative recovery was good and antibiotics were given for 4 days (ceftriaxone + metronidazole). The patient was diseharged from hospital on the $7^{\text {th }}$ day after laparotomy. After review of the literature the authors concluded that this case of pneumoperitoneum was probably related to infection by a gas-producing bacterium in a patient with clinical findings of paralytic ileus.

KEY WORDS: Pneumoperitoneum. Postoperative complications. Cesarean section. Puerperium.

\section{Referências}

1.Bevan PG. Incidence of postoperative pneumoperitoneum and its signficance. Br Med J 1961; 2: 605-8.

2.Cantiello L, Laghi A, Ferrara I, Lauro C. Ogilvie syndrome. Report of two cases. Minerva Ginecol 1996; 48: 211-4.

3.Carrelet T, Collet M, Frost E. Pelvipéritonite à Escherichia coli associée à un pneumopéritoine. Presse Méd 1988; 17: 751-2.
4.Catalano O, Grassi R, Rotondo A. Diagnosis of free air in the abdomen. Role of echography. Radiol Med 1994; 87: 632-5.

5.Earls JP, Dachman AH, Colon E, Garrett MG, Molloy M. Prevalence and duration of postoperative pneumperitoneum: sensitivity of CT vs left lateral decubitus radiography. Am J Roentgenol 1993: 161: 781-5.

6.Ferrara BE, Harrison WD. Pneumoperitoneum. J Fla Med Assoc 1991; 78: 81-4.

7.Givarc'h M, Hakim M, Roullet-Audy JC. Ogilvie's syndrome or colonic pseudo-obstruction. A propos of 26 cases. J Chir 1996; 133: 301-6.

8.Hill HF, Bunting J, Wood RD, Temple JE. The significance of radiological pneumoperitoneum in the diagnosis of postoperative peritonitis. J R Coll Surg Edinb 1978; 23: 303-4.

9.Hoover EL, Cole GD, Mitchell LS, Adams CZ Jr, Hassett J. Avoiding laparotomy in nonsurgical pneumoperitoneum. Am J Surg 1992; 164: 99-103.

10.Kandylakis S, Makrigiannakis N, Mirra N, Perpyrakis G, Kontakis K. Pneumoperitoneo senza perforazione. Minerva Chir 1993; 48: 717-20.

11.Lai FC, Wu CC, Hwu DH, Liu TJ, Péng FK. Pneumoperitoneum caused by spontaneous bacterial peritonitis: a case report. Chung Hua I Tsulh Tsa Chih 1994; 54: 373-5.

12.Menuck L, Siemers PT. Pneumoperitoneum: importance of right upper quadrant features. Am J Roentgenol 1976; 127: 753-6.

13.Miller RE, Becker GJ, Slabaugh RD. Nonsurgical pneumoperitoneum. Gastrointest Radiol 1981; 6: 73-4.

14. Ogilvie H. Large intestine colic dilatation due to sympathetic deprivation: a new clinical syndrome. Br Med J 1948: 2: 671-3.

15.Tenembaum M; Bauer JJ, Gelernt IM, Kreel I, Aufses AH Jr. Postoperative pneumoperitoneum: an unusual etiology. Ann Surg 1978; 188: 769-72.

16.Vitale G, Mancuso P, Linciano M, Binotto F, Tinti S, Torresin L, et al. La sindrome di Ogilvie dopo taglio cesareo. Contributo clinico. Minerva Ginecol 1990; 42: 69-72.

17.Zanetti PP; Gagna G, Obialero M. Il pneumoperitoneo post-operatorio: incidenza, significato, durata. Arch Sci Med 1982; 139: 219-20. 